\title{
LAS CARACTERÍSTICAS DEL ARBITRAJE DEL CIADI
}

\author{
Gabriela ÁLVAREZ ÁVILA*
}

RESUMEN: El Centro Internacional de Arreglo de Diferencias relativas a Inversiones (CIADI) es una organización internacional creada en 1965 como resultado de una iniciativa del Banco Mundial. Actualmente 134 estados son partes de ella. La autora describe el alcance de la jurisdicción del centro (además de describir otras actividades, tales como: procedimientos de conciliación y arbitraje cuando una de las partes no es miembro del CIADI; disputas que no emanan directamente de una inversión; y procedimientos de establecimiento de hechos). La característica más importante de estos procedimientos es su independencia respecto al derecho interno de los estados parte del Convenio del CIADI. Se describen los requisitos generales para instituir procedimientos de arbitraje, así como las facultades concedidas al tribunal, dándonos a través de un lenguaje claro y conciso una visión amplia de lo que es el CIADI.

ABSTRACT: The International Centre for the Settlement of Investment Disputes (ICSID) is an international organization created in 1965 as a result of the initiative of the World Bank. Today 134 countries are parties to it. The author describes the scope of the jurisdiction of the Centre (among other things: conciliation and arbitration proceedings when one of the parties is not a member to the ICSID; disputes not arising directly from investment issues; and fact-finding proceedings). The most relevant characteristic of the ICSID proceedings is that they are independent from the national legislation of the parties to the ICSID Convention. The general characteristics of the institution of proceedings, as well as the powers conferred upon the tribunal are described, in a clear and concise language that provides us with a wide view of what ICSID is.

RESUMÉ: Le Centre International pour le Règlement des Différends relatifs aux Investissements (CIRDI) est une organisation internationale créée en 1965, résultat d'une initiative de la Banque Mondiale. Actuellement 134 Etats font parties de cette organisation. L'auteur décrit la portée de la juridiction du Centre (outre, la description des autres activités du Centre, telles que: les procédures de conciliation et d'arbitrage lorsque l'une des parties n'est pas membre du CIRDI; les différends qui ne sont pas en relation directe avec un investissement; et les procédures de constatations des faits). La caractéristique la plus importante des procédures CIRDI est leur indépendance vis-à-vis du droit interne des Etats contractants de la Convention. L'auteur décrit les conditions générales pour entamer des procédures d'arbitrage, ainsi que les facultés octroyées au tribunal, nous donnant ainsi, grâce à l'utilisation d'un langage clair et concis, une vision vaste de ce qu'est le CIRDI.

* Consejero Jurídico del CIADI. 
SUMARIO: I. Introducción. II. Creación del CIADI y su objeto. III. Actividades del CIADI. IV. Jurisdicción del centro. V. El arbitraje del CIADI es autónomo e independiente. VI. Conclusión.

\section{INTRODUCCIÓN}

El arbitraje internacional tiene una gran importancia en el desarrollo de las relaciones comerciales internacionales. Sin embargo, no es hasta hace algunos años que el arbitraje internacional empieza realmente a desarrollarse en América Latina. En este contexto, nos parece relevante el papel que el Centro Internacional de Arreglo de Diferencias relativas a Inversiones (CIADI) puede jugar. En efecto, un importante número de países latinoamericanos ${ }^{1}$ son Estados contratantes del Convenio sobre Arreglo de Diferencias relativas a Inversiones entre Estados y nacionales de otros Estados de 1965, el Convenio del CIADI. ${ }^{2}$ De esta manera, la presente contribución tiene por objetivo analizar las principales características del centro y sus actividades, no sin antes destacar los motivos de su creación y su objeto. Cabe señalar que en virtud de que la actividad más importante del centro se concentra en los procedimientos de arbitraje, nos limitaremos a abordar ciertos puntos esenciales del arbitraje, tales como: la manera de iniciar el mismo, la constitución y poderes del tribunal, y algunos aspectos relacionados con el laudo y los recursos posteriores al mismo.

\section{CREACIÓN DEL CIADI Y SU OBJETO}

El CIADI es una organización internacional de carácter público creada mediante un tratado internacional: el Convenio sobre Arreglo de Diferencias relativas a Inversiones entre Estados y Nacionales de otros Estados de $1965 .{ }^{3}$ Hasta la fecha actual,141 Estados han firmado el convenio

1 Para obtener una lista actualizada de los Estados contratantes véase: www.worldbank.org/icsid (rubro ICSID publications/list of contracting states).

2 Los dos Estados más importantes de América Latina que no son Estados contratantes del convenio son Brasil y México. Sin embargo, aún cuando México no es Estado contratante del CIADI, se han iniciado a la fecha seis arbitrajes en su contra bajo las reglas del Mecanismo Complementario del CIADI.

3 El convenio se acompaña de un Reglamento Administrativo y Financiero, de Reglas Procesales Aplicables a la Iniciación de los Procedimientos de Conciliación y Arbitraje (Reglas de Iniciación), de Reglas Procesales Aplicables a los Procedimientos de Arbitraje (Reglas de Arbitraje) y de las Reglas Procesales Aplicables a los Procedimientos de Conciliación (Reglas de Conciliación). 
y 134 la han ratificado. El establecimiento de está organización fue una iniciativa del Banco Mundial para fomentar las inversiones de países industrializados a países en desarrollo. ${ }^{4} \mathrm{El}$ interés del banco de establecer una organización de esta naturaleza está comprendida en el marco de sus actividades. ${ }^{5}$

En efecto, entre sus actividades, el grupo del Banco Mundial busca la promoción de la inversión extranjera hacía países en desarrollo, con el fin de que se lleven a cabo proyectos productivos. Por lo general, las inversiones extranjeras son bien recibidas en los países en desarrollo, sin embargo las condiciones en las que operan dichas inversiones representan siempre un riesgo de controversia entre el país receptor de la inversión y el inversionista. En estas controversias también se puede ver envuelto el Estado de cual es nacional el inversionista.

Así, el Banco Mundial, al fomentar la creación del Convenio del CIADI buscaba mejorar la atmósfera de confianza mutua entre el inversionista y el Estado receptor, y así favorecer el incremento de la inversión extranjera en los países en desarrollo. Además, como el doctor Shihata lo indica: "ICSID is intended to complement the work of the World Bank in reducing non-commercial deterrents to FDI [Foreign Direct Investment], as well as other forms of investment" ${ }^{6}$

Por otra parte, en varias ocasiones se solicitó al presidente del Banco Mundial sus buenos oficios para que mediara entre un Estado y un inversionista; llegó incluso a ser conciliador y hasta árbitro. ${ }^{7}$ Estas solicitudes confirmaban la necesidad de crear una organización independiente que se encargara del arreglo de diferencias entre Estados e inversionistas privados, y que además garantizara un equilibro entre los intereses de ambas partes.

Fue a partir de la resolución núm. 174 de la Junta de Gobernadores de fecha 18 de septiembre de 1962, que se autorizó a los directores ejecutivos a estudiar la viabilidad de establecer una organización que se ocupara de la resolución de diferencias entre Estados e inversionistas, mediante

4 Informe de los Directores Ejecutivos acerca del Convenio sobre Arreglo de Diferencias Relativas a Inversiones entre Estados y Nacionales de Otros Estados, ICSID, Doc. 2, pp. 4 y 5.

5 Véase artículo 1o. del Convenio Constitutivo del Banco Internacional de Reconstrucción y Fomento.

6 Shihata, Ibrahim F. I., The World Bank in Changing World, Franziska Tschofen y Antonio R. Parra (eds.), Londres, Martinus Nijhoff Publishers, 1991, p. 267.

7 Ibidem, pp. 289 y ss. 
procedimientos de conciliación y arbitraje. ${ }^{8}$ A partir de 1963 , juristas de 86 países se reunieron ante la solicitud del presidente del Banco Mundial, en Addis-Abeba (16 al 20 de diciembre de 1963), y posteriormente en Santiago de Chile (3 al 7 de febrero de 1964), en Ginebra (17 al 21 de febrero de 1964) y en Bangkok (27 de abril a 1 de mayo de 1964) para discutir el proyecto de Convenio del CIADI preparado por el personal del banco. Después de otras reuniones de un Comité Legal, formado por representantes de 61 Estados miembros, con los directores ejecutivos del banco, éstos últimos sometieron a consideración de los gobiernos miembros del banco el texto del Convenio del CIADI el 18 de marzo de $1965 .{ }^{9}$ El convenio entró en vigor el 14 de octubre de 1966.

Como se indicó, uno de los objetos del convenio es fomentar las inversiones extranjeras privadas otorgando una mayor seguridad jurídica tanto al inversionista como al Estado receptor. Así, el CIADI es, gracias a las disposiciones del convenio, un foro neutral y autónomo que mantiene el equilibrio entre los intereses de los inversionistas y de los Estados para la resolución de conflictos en materia de inversiones.

Con el fin de ampliar el marco de las actividades del CIADI, el 27 de septiembre de 1978, el Consejo Administrativo del centro autorizó al Secretariado del CIADI a administrar procedimientos que estén fuera del alcance del Convenio del CIADI. Con este objetivo se emitieron las Reglas del Mecanismo Complementario, por medio de las cuales el Secretariado puede administrar los siguientes tipos de procedimientos: a) procedimientos de conciliación y de arbitraje en materia de inversiones entre un Estado y un inversionista, cuando el Estado parte en el procedimiento, o bien el Estado del cual es nacional el inversionista, no es un Estado contratante del convenio; ${ }^{10}$ b) aquellos procedimientos de conciliación y de arbitraje para el arreglo de diferencias que no surjan directamente de una inversión

8 ICSID, History of the ICSID Convention. Documents Concerning the Origin and the Formulation of the Convention on the Settlement of Investment Disputes between States and Nationals of Other States, Washington, D. C., ICSID, vol. II-1, p. 51.

9 Op. cit., nota 4, pp. 1-3. Este texto había sido previamente aprobado por la Junta de Gobernadores del banco el 10 de septiembre de 1964, durante la reunión anual del Banco en Tokio. En esa oportunidad, los países latinoamericanos (Argentina, Bolivia, Brasil, Chile, Colombia, Costa Rica, República Dominicana, Ecuador, El Salvador, Guatemala, Haití, Honduras, México, Nicaragua, Panamá, Paraguay, Perú, Uruguay y Venezuela) e Irak votaron en contra. Ese voto en contra se conoce como el "No de Tokio". Véase ICSID, op. cit., nota 8, p. 606. Actualmente todos estos países (con excepción de Brasil y México) han firmado o ratificado el convenio.

10 Artículos 2o.(a) y 4o.(2) del Reglamento del Mecanismo Complementario, publicado en www.worldbank.org/icsid (rubro ICSID publications). 
y en donde al menos una de las partes es un Estado contratante o un inversionista de un Estado contratante, siempre y cuando no se trate de una transacción comercial ordinaria; ${ }^{11}$ y $c$ ) procedimientos de comprobación de hechos.

\section{ACTIVIDADES DEL CIADI}

El CIADI además de tener como principal actividad la administración de procedimientos de arbitraje y de conciliación, realiza varias publicaciones y actividades de asesoría. De esta manera, el CIADI publica una revista semestral especializada en el derecho de las inversiones, intitulada ICSID Review Foreign Investment Law Journal, así como un boletín, News from ICSID, que tiene por objeto informar de las actividades del centro y publicar breves artículos sobre temas de interés. Además publica una colección de leyes sobre inversión, Investment Laws of the World y una colección de tratados de inversión, Investment Treaties, que se actualizan periódicamente. El Secretariado del CIADI ${ }^{12}$ ocasionalmente presta también asesoría en materia de arbitraje y de legislación sobre inversiones.

Adicionalmente, el secretario general del CIADI es frecuentemente designado como autoridad nominadora de árbitros en tratados sobre inversión o en cláusulas compromisorias. Así, en el año fiscal 2000, el secretario general atendió dos solicitudes de nombramiento de árbitros en dos casos iniciados al amparo del Reglamento de Arbitraje de la Comisión de las Naciones Unidas para el Derecho Mercantil Internacional (CNUDMI). El primero de ellos fue un caso iniciado bajo el capítulo sobre inversiones del Tratado de Libre Comercio de América del Norte (TLCAN) y el segundo un caso iniciado en el marco de un tratado bilateral de inversión. ${ }^{13}$ El Reglamento de la CNUDMI otorga a la autoridad nominadora la responsabilidad de resolver las recusaciones de árbitros presentadas por las partes. Durante el ejercicio 2000, el secretario general resolvió dos de estas recusaciones, ${ }^{14} \mathrm{y}$ durante el presente ejercicio fiscal

11 Ibidem, artículos 2o.(b) y 4o.(3).

12 Actualmente el Secretariado del CIADI se integra por el secretario general, el secretario general adjunto y por el personal del centro. El secretario general es el representante legal y el funcionario principal del centro. Véanse artículos 9o. a 11 del convenio.

13 CIADI, Informe anual 2000, p. 4, en: www.worldbank.org/icsid (rubro ICSID publications).

14 Idem. 
decidió tres más, en una de ellas el procedimiento se había iniciado al amparo del capítulo XI del TLCAN, y en las dos restantes los procedimientos se habían iniciado al amparo de tratados bilaterales. ${ }^{15}$

El Convenio del CIADI prevé la posibilidad de iniciar tanto procedimientos de conciliación como procedimientos de arbitraje. A la fecha sólo han habido tres procedimientos de conciliación, ${ }^{16}$ mientras que se han iniciado 86 procedimientos de arbitraje, de los cuales 76 conforme al convenio y 10 al amparo del Mecanismo Complementario del CIADI. ${ }^{17}$ Es importante destacar que 50 procedimientos de arbitraje, o sea más de la mitad, se han iniciado en los últimos cuatro años.

Esto último se debe al gran número de tratados bilaterales de inversión y a los cuatro tratados multilaterales que incluyen al CIADI como una opción para el arreglo de diferencias que surjan entre Estados e inversionistas al amparo de dichos tratados. ${ }^{18}$ Hasta este momento, 34 procedimientos de arbitraje se han iniciado con base en un tratado bilateral, ocho procedimientos con base en el TLCAN, y en el año fiscal que acaba de concluir, el CIADI registró además una solicitud de arbitraje que invocó tanto un tratado bilateral como el Tratado de la Carta de la Energía.

Debido a que la actividad del centro en su gran mayoría se concentra en la administración de procedimientos de arbitraje bajo el convenio, la presente contribución se limitará a esta actividad, no sin hacer alguna referencia al Mecanismo Complementario por la importancia que éste tiene respecto a la aplicación del TLCAN.

15 CIADI, Informe anual 2001, por publicarse, www.worldbank.org/icsid. Adicionalmente, el secretario general nombró a un mediador en un procedimiento de mediación ad hoc.

16 SEDITEX Engineering Beratungsgesellschaft für die Textilindustrie m. b. h. c. República de Madagascar, Caso CIADI CONC/82/1; Tesoro Petroleum Corporation c. Trinidad y Tobago, Caso CIADI CONC/83/1; SEDITEX Engineering Beratungsgesellschaft für die Textilindustrie m. b. h. c. República de Madagascar, Caso CIADI CONC/94/1.

17 El Mecanismo Complementario ha sido principalmente utilizado en procedimientos incoados al amparo del TLCAN, pues tanto México como Canadá no son Estados contratantes del CIADI. Así, de los 10 procedimientos iniciados bajo el Mecanismo Complementario, cinco han sido incoados en contra de México bajo el TLCAN, tres en contra de Estados Unidos bajo el TLCAN, uno en contra de México bajo el tratado bilateral México-España, y uno en contra de Ucrania bajo el tratado bilateral Ucrania-Estados Unidos.

18 Los tratados multilaterales que a la fecha incluyen la posibilidad de recurrir al CIADI, ya sea bajo el convenio o bajo el Mecanismo Complementario, son: El Tratado de Libre Comercio de América del Norte, el Tratado de la Carta de la Energía, el Tratado de Libre Comercio entre Colombia, México y Venezuela, y los protocolos sobre el tratamiento de las inversiones originadas dentro y fuera del área del Mercosur de 1994. 


\section{JURISDICCIÓN DEL CENTRO}

El arbitraje del CIADI tiene dos importantes características que delimitan la jurisdicción del centro: se trata de un procedimiento eminentemente consensual y especializado. Así, en este apartado nos referiremos, por una parte, a la importancia y particularidades del consentimiento en el arbitraje del CIADI, y por la otra, explicaremos que la especialización del centro gira alrededor de dos ejes: su competencia ratione personae y su competencia ratione materiae.

\section{Consentimiento}

El consentimiento en el sistema del CIADI se ha calificado como la "piedra angular en la que descansa la jurisdicción del centro" ${ }^{19} \mathrm{El}$ consentimiento al arbitraje debe darse por el inversionista de un Estado contratante y el Estado parte en la diferencia por escrito, y conforme a lo establecido por el artículo 25 del convenio. Es importante señalar que aún cuando exista un consentimiento claro y por escrito de un inversionista y de un Estado para someter sus diferencias a arbitraje, si el Estado de donde es nacional el inversionista o el Estado parte en la diferencia no son Estados contratantes del Convenio de Washington, no podrá iniciarse un procedimiento de arbitraje ante el CIADI. ${ }^{20}$

El consentimiento escrito de ambas partes al arbitraje debe existir al momento de presentar la solicitud de arbitraje al centro. ${ }^{21}$ Sin embargo, el convenio no precisa la fecha en la que se tiene que otorgar el consentimiento al arbitraje. En efecto, el informe de los directores ejecutivos indica que el consentimiento puede contenerse en un tratado de inversión, señalando que las diferencias a las que pueda dar lugar dicho tratado podrán someterse al centro; o bien en un compromiso arbitral entre las partes relativo una diferencia ya existente. El informe indica también que el consentimiento no debe de expresarse en el mismo acto jurídico. Así un Estado puede ofrecer en su legislación sobre promoción de inversiones la

19 Op. cit., nota 4, p. 9.

20 El Mecanismo Complementario del CIADI es aplicable cuando el Estado parte en la diferencia o el Estado de donde es nacional el inversionista no son Estados contratantes del convenio. Sin embargo, la aplicación del Mecanismo Complementario no es automática, se requiere un consentimiento por escrito de las partes indicando la aplicación de las Reglas del Mecanismo Complementario. A este respecto, véanse los artículos 2o. y 4o. del Reglamento del Mecanismo Complementario del CIADI.

21 Artículo 36(2) del convenio. 
opción de recurrir al arbitraje del CIADI para dirimir diferencias relativas a cierta clase de inversiones, y el inversionista puede consentir por escrito aceptando dicha oferta. ${ }^{22}$ En la práctica, alrededor de 30 Estados han seguido esta sugerencia, incorporando en su legislación sobre promoción de inversiones al CIADI como foro idóneo para resolver las diferencias por medio de un arbitraje. ${ }^{23}$ Además, aún un mayor número de Estados decidieron incorporar esta oferta de arbitraje del CIADI en tratados bilatera$\operatorname{les}^{24} \mathrm{o}$ multilaterales. Este tipo de arbitraje se le ha llamado en inglés "arbitration without privity", ${ }^{25}$ lo que equivaldría a una oferta pública de arbitraje. Esta práctica también ha hecho que el número de procedimientos de arbitraje ante el centro se haya multiplicado de manera exponencial. Sin embargo, este consentimiento en un tratado de inversión generalmente va acompañado de una serie de condiciones que hay que cumplir previamente al inicio del arbitraje. Entre las más comunes se encuentran: un periodo de negociaciones para intentar alcanzar un arreglo amigable ${ }^{26}$ que no se haya sometido la diferencia a los tribunales locales del país receptor de la inversión; y que la diferencia esté comprendida en el marco del tratado.

\section{Competencia ratione personae}

Como se mencionó anteriormente, la competencia del centro está limitada a diferencias entre un Estado contratante y un nacional de otro Estado contratante. Analizaremos sucesivamente lo que, por una parte, el convenio incluye dentro del término "un Estado contratante", y por otra parte, lo que el convenio define como "un nacional de otro Estado contratante".

22 Op. cit., nota 4, p. 9.

23 Este es el caso de la Ley de Promoción y Protección de Inversiones de Venezuela, promulgada mediante decreto núm. 356 con fecha 3 de octubre de 1999.

24 De los aproximadamente 2000 tratados bilaterales de inversión concluidos a la fecha, alrededor de 1500 refieren al arbitraje del CIADI como una opción para dirimir las controversias. Para el número de tratados bilaterales véase UNCTAD, World Investment Report 2000, Ginebra, United Nations, 2000, pp. 7 y 8.

25 Paulsson, Jan, “Arbitration Without Privity”, ICSID Review-Foreign Investment Law Journal, vol. 10, núm. 2, 1995, pp. 232-257.

26 El periodo de negociaciones puede variar, en ocasiones es de tres meses, en otras de seis meses e inclusive hasta de un año. 


\section{A. Estado contratante}

El artículo 25 del convenio señala lo siguiente: "La jurisdicción del centro se extenderá a las diferencias... entre un Estado contratante (o cualquier subdivisión política u organismo público de un Estado contratante acreditados ante el centro por dicho Estado)...".

Esta indicación en el convenio tiene una particular importancia. En efecto, las diferencias, en principio, sólo pueden existir respecto del Estado contratante, y por lo tanto sólo el Estado podría ser parte en un procedimiento de arbitraje, a diferencia de una subdivisión política u organismo público. Sin embargo, esto admite una excepción cuando el mismo Estado ha designado ante el centro las subdivisiones políticas u organismos públicos que podrían ser en sí mismos, partes en un procedimiento de arbitraje. A la fecha sólo diez Estados han hecho este tipo de designaciones. ${ }^{27}$ Adicionalmente a esta designación, el convenio requiere que el consentimiento de una subdivisión política o de un organismo público sea aprobado por el Estado, ${ }^{28}$ salvo que el Estado haya notificado al centro que esta aprobación no es necesaria. ${ }^{29}$ Estas designaciones y aprobaciones se pueden también hacer de modo ad hoc.

\section{B. Nacional de un Estado contratante}

El convenio diferencia entre un nacional persona física y un nacional persona jurídica, y establece para cada uno de ellos ciertos requisitos.

\section{a. Persona física}

El convenio da la capacidad a una persona física de someter al centro diferencias con un Estado bajo ciertas condiciones que son: $a$ ) al momento del consentimiento de las partes al arbitraje y $b$ ) al momento del registro de la solicitud de arbitraje, la persona debe tener la nacionalidad de un Estado contratante distinto del Estado parte en la diferencia; y $c$ ) la persona no puede tener también la nacionalidad del Estado parte en la diferencia en ninguna de las dos fechas antes mencionadas.

27 Australia, Ecuador, Guinea, Kenia, Madagascar, Nigeria, Perú, Portugal, Sudán y Reino Unido. Véase: http://www.worldbank.org/icsid/pubs/icsid-8/icsid-8-c.htm.

28 Artículo 25(3) del convenio.

29 Australia, Perú, Portugal y Reino Unido han hecho este tipo de notificaciones al centro. Véase: http://www.worldbank.org/icsid/pubs/icsid-8/icsid-8-c.htm. 
De acuerdo con este último requisito, un inversionista que sea doble nacional de un Estado contratante y del Estado parte en la diferencia en cualquiera de las dos fechas críticas señaladas en el artículo 25(2)(a), no podrá incoar un procedimiento de arbitraje ante el CIADI. El objetivo es evitar una confrontación entre una persona y el Estado del cual es nacional, así como el de obviar los problemas muy complejos de doble nacionalidad. ${ }^{30}$ Además, el problema de la doble nacionalidad no se puede salvar ${ }^{31}$ mediante el consentimiento del Estado de considerar a la otra parte como nacional de otro Estado contratante. ${ }^{32}$ En este caso, la regla de personas jurídicas que se explicará en el próximo apartado no se aplica.

Así pues, la nacionalidad es un elemento clave para definir los límites en que un nacional, persona física, de un Estado contratante puede someter una diferencia a arbitraje al amparo del convenio. A la fecha ha habido 13 casos iniciados por personas físicas ante el CIADI, ${ }^{33}$ de estos casos, en dos el Estado parte ha interpuesto objeciones a la jurisdicción, alegando que alguna(s) de estas condiciones no se ha cumplido cabalmente.

30 ICSID, History of the ICSID Convention. Documents Concerning the Origin and the Formulation of the Convention on the Settlement of Investment Disputes between States and Nationals of Other States, Washington, D. C., ICSID, vol. III, p. 162. Respecto a los problemas de doble nacionalidad véase: Rezek, José Francisco, "Le droit international de la nationalité", Recueil des Cours, La Haya, vol. III, 1986, pp. 334-400. Nottebohm (Liechtenstein v. Guatemala), Judgment of April 6, 1955, ICJ Reports, 1955.

31 Esto puede ser particularmente relevante para tratados como el TLCAN, el cual no tiene ninguna restricción en cuanto a la doble nacionalidad. Así, un doble nacional que desee incoar un procedimiento bajo el TLCAN no podrá hacerlo conforme al Convenio del CIADI o al Mecanismo Complementario del CIADI y tendrá como única opción el Reglamento de la CNUDMI.

32 Broches, Aron, "The Convention on the Settlement of Investment Disputes between States and National of other States", RCADI, t. 136, núm. II, 1972, p. 358.

33 A saber: Ghaith R. Pharaon c. República de Túnez (Caso CIADI núm. ARB/86/1), Philippe Gruslin c. Malasia (Caso CIADI núm. ARB/94/1), Antoine Goetz y Otros c. República de Burundi (Caso CIADI núm. ARB/95/3), Robert Azinian y Otros c. Estados Unidos Mexicanos (Caso CIADI núm. ARB(AF)/97/2), Emilio Agustín Maffezini c. Reino de España (Caso CIADI núm. ARB/97/7), Joseph C. Lemire c. Ucrania (Caso CIADI núm. ARB(AF)/98/1), Eudoro A. Olguín c. República de Paraguay (Caso CIADI núm. ARB/98/5), Víctor Pey Casado y Fundación presidente Allende c. República de Chile (Caso CIADI núm. ARB/98/2), Alex Genin y Otros c. República de Estonia (Caso CIADI núm. ARB/99/2), Philippe Gruslin c. Malasia (Caso CIADI núm. ARB/99/3), Marvin Roy Feldman Karpa c. Estados Unidos Mexicanos (Caso CIADI núm. ARB(AF)/99/1), Patrick Mitchell c. República Democrática del Congo (Caso CIADI núm. ARB/99/7), Antoine Goetz y Otros c. República de Burundi (Caso CIADI núm. ARB/01/2). En algunos de estos casos existen decisiones publicadas, para obtener los datos de publicación hay que referirse a la página de Internet del centro: www.worldbank.org/icsid (rubro ICSID Cases). 


\section{$b$. Persona jurídica}

El artículo 25(2)(b) del convenio se refiere a la persona jurídica e incluye dos supuestos. En primer lugar se indica que cualquier persona jurídica que, hasta la fecha del consentimiento de las partes, sea nacional de un Estado contratante distinto del Estado parte, a la diferencia podrá presentar una solicitud de arbitraje. El convenio no indica el criterio para definir la nacionalidad de una persona jurídica. Sin embargo, dos criterios han sido invocados como pertinentes para definir la nacionalidad de una persona jurídica en la jurisprudencia internacional ${ }^{34} \mathrm{y}$ en la jurisprudencia del CIADI, ${ }^{35}$ a saber: el lugar de constitución y el lugar del domicilio principal. Lo anterior sin perjuicio de que las partes consideren otros criterios como pertinentes. ${ }^{36}$

$\mathrm{Al}$ parecer la definición del término "nacional de otro Estado contratante" es bastante incluyente. Por ejemplo, el señor Broches indicó que: "It would seem, therefore, that for the purposes of the Convention a mixed economy company or government-owned corporation should not be disqualified as 'national of another Contracting State' unless it is acting as an agent for the government or is discharging an essentially governmental function". 37

El segundo supuesto que incluye el convenio es aquella persona jurídica que, siendo nacional del Estado parte en la diferencia en la fecha del consentimiento de las partes al arbitraje, las partes hayan acordado conferirle el carácter de nacional de un Estado contratante distinto del Estado parte para los fines del convenio por estar sometida a control extranjero.

Este segundo supuesto refleja la realidad económica de los proyectos de inversión. En efecto, en muchas ocasiones los Estados receptores de inversión exigen la constitución de una sociedad local que constituya el vehículo de la inversión. Este segundo supuesto ha dado lugar a discusión

34 Véase Barcelona Traction, Light and Power Company Limited (Belgium v. Spain), Judgment of February 5, 1970, ICJ Reports, 1970, p. 42.

35 Véase, por ejemplo, Amco Asia Corporation y Otros c. República de Indonesia (Caso CIADI núm. ARB/81/1), Decisión sobre competencia del 25 de septiembre de 1985, ICSID Reports, vol. 1, p. 398.

36 Véase a este respecto: Broches, Aron, op. cit., nota 32, p. 361; Amerasinghe, C. F., "Jurisdiction ratione personae under the Convention on the Settlement of Investment Disputes Between States and Nationals of Others States", The British Yearbook of International Law, 1974, pp. 212214, 256.

37 Broches, Aron, op. cit., nota 32, p. 355. 
en varios laudos o decisiones sobre competencia del centro. En algunos se ha discutido si el acuerdo de las partes debe ser explícito o tácito. ${ }^{38}$

Respecto al término de "control extranjero", el convenio no da ninguna precisión y esto ha dado lugar a que el tema se haya abordado por algunos tribunales del centro. ${ }^{39}$ Las partes gozan de una amplia discreción para poder definir lo que consideran control extranjero. Sin embargo, esa definición debe ser razonable, ya que se trata de un concepto objetivo ${ }^{40} \mathrm{y}$ por lo tanto la definición de las partes no puede ir en contra de los fines y objeto del convenio.

\section{Competencia ratione materiae}

La competencia ratione materiae tiene dos aspectos, a saber: se pueden someter al centro únicamente diferencias de naturaleza jurídica, y la diferencia debe surgir directamente de una inversión. Ni la expresión "diferencia de naturaleza jurídica", ni el término "inversión" están definidos en el convenio.

Respecto a la naturaleza jurídica de la diferencia, en los trabajos preparatorios del convenio se hizo hincapié en el hecho de que éstas no podían incluir diferencias meramente políticas o comerciales, ${ }^{41}$ y que se entendía que esta expresión requería de la existencia de un derecho o una obligación jurídicos. ${ }^{42}$

El informe de los directores ejecutivos señala a este respecto que:

38 Véase a este respecto, por ejemplo: Lalive, Pierre, “The First 'World Bank' Arbitration (Holiday Inn v. Morocco) some Legal Problems", The British Yearbook of International Law, 1980, p. 141; Amco Asia..., cit., nota 35, pp. 392 y ss.; Klöckner Industrie-Anlagen Gmbh y Otros c. República del Camerún, Laudo del 21 de octubre de 1983, ICSID Reports, vol. 2, pp. 16 y 17; Liberian Eastern Timber Corporation c. República de Liberia (Caso CIADI núm. ARB/83/2), Decisión sobre competencia del 24 de octubre de 1984, reproducida en el laudo del 31 de marzo de 1986, ICSID Reports, vol. 2, pp. 351-354.

39 Véase, por ejemplo: Liberian Eastern..., cit., nota 38, pp. 351 y 352. Vacuum Salt Products Limited c. Gobierno de la República de Ghana, laudo del 16 de febrero de 1994, ICSID Reports, vol. 2, pp. 334 y ss. Véase también: Lamm, Caroly B. y Cohen Smutny, Aby, "The Implementation of ICSID Arbitration Agreements", ICSID Review Foreign Investment Law Journal, vol. 11, núm. 1, 1996, p. 76.; Broches, Aron, "Denying ICSID Jurisdiction. The ICSID Award in Vacuum Salt Products Limited”, Journal of International Arbitration, núm. 3, vol. 13, 1996, pp. 21-30.

40 Schreuer, Christoph, "Commentary on the ICSID Convention: Article 25", ICSID Review. Foreign Investment Law Journal, vol. 11, núm. 1, 1997, pp. 113, 117. Véase también: Vacuum Salt..., cit., nota 39, pp. 334 y ss.

41 ICSID, op. cit., nota 8, pp. 54, 83, 96.

42 Ibidem, pp. 267, 285, 322 y 565. 
La expresión 'diferencia de naturaleza jurídica' se ha utilizado para dejar aclarado que están comprendidos dentro de la jurisdicción del centro los conflictos de derechos, pero no los simples conflictos de intereses. La diferencia debe referirse a la existencia o al alcance de un derecho u obligación de orden legal, o a la naturaleza o al alcance de la reparación a que dé lugar la violación de una obligación de orden legal. ${ }^{43}$

Respecto a la definición del término inversión, aún cuando se emitieron durante los trabajos preparatorios opiniones a favor de definir dicho término, ${ }^{44}$ el señor Broches, consejero jurídico del banco y presidente durante las reuniones de discusión del proyecto, se opuso a ello. ${ }^{45}$ Así, la omisión fue voluntaria, con el fin de dar la mayor amplitud al término de inversión. ${ }^{46}$

Los directores ejecutivos señalaron a este respecto que "no se [había] intentando definir el término 'inversión', teniendo en cuenta el requisito esencial del consentimiento de las partes y el mecanismo mediante el cual los Estados contratantes pueden dar a conocer de antemano, si así lo desean, las clases de diferencias que estarán o no dispuestos a someter a la jurisdicción del centro (artículo 25(4))" ${ }^{47}$

Cabe señalar que el convenio en el artículo 25(4) otorga a los Estados contratantes la posibilidad de informar al centro la clase o clases de diferencias que aceptarían someter, o no, a su jurisdicción. Este tipo de notificación no constituye de ninguna manera una reserva al convenio. Esta disposición se incluyó como respuesta a opiniones expresadas por ciertos Estados de que la adhesión al convenio podría malinterpretarse y crear expectativas de que los Estados contratantes considerarían favorablemente las solicitudes de los inversionistas encaminadas a someter diferencias a la jurisdicción del centro. ${ }^{48}$ Además algunos Estados deseaban limitar la jurisdicción del centro a cierto tipo de diferencias. ${ }^{49}$ De igual manera, esta disposición reafirma la necesidad del consentimiento escrito del Estado

43 Op. cit., nota 4, pp. 9 y 10. La Corte Permanente de Justicia Internacional y la Corte Internacional de Justicia también han indicado lo que es una diferencia jurídica. Al respecto véase: The Mavrommatis Palestine Concessions (Greece v. United Kingdom), Judgment of August 30th, 1924, PCIJ, Collection of Judgments, Series A, núm. 2, 1924, p. 11. Case Concerning East Timor (Portugal v. Australia), Judgment of June 30, ICJ Reports, 1995, pp. 89 y 99.

44 Véase, por ejemplo, ICSID, op. cit., nota 8, pp. 182, 261, 450, 568.

45 Ibidem, pp. 22, 54, 203 y 204, 395, 451.

46 Ibidem, p. 83.

47 Op. cit., nota 4, p. 10.

48 Ibidem, p. 10.

49 ICSID, op. cit., nota 8, pp. 57 y 59, 376 y 377, 882 y 823. 
para someter una diferencia a un procedimiento de arbitraje o conciliación. ${ }^{50}$ En efecto, el hecho de que un Estado informe qué tipo de diferencias estaría dispuesto a someter al centro o la indicación de cuáles no estaría dispuesto a someter es independiente del consentimiento de dicho Estado al arbitraje. Podría darse el caso que el Estado excluya ciertas diferencias en su notificación, sin que esto tenga efecto alguno en el caso de que el Estado consienta al arbitraje en un contrato o tratado de inversión, en las cuales no haya excluido tales tipos de diferencias. ${ }^{51}$

Algunos laudos o decisiones se han referido al término de inversión. ${ }^{52}$ Además, es importante señalar que cuando un inversionista invoca como fundamento para el consentimiento del Estado, por ejemplo, un tratado bilateral, estos instrumentos invariablemente definen lo que se debe entender como inversión. De esta manera, principalmente en los tratados de inversión se encuentran definiciones muy amplias. Sin embargo, independientemente de lo que pueda disponer un tratado de inversión, el término inversión debe analizarse a la luz del Convenio del CIADI. Esto fue claramente señalado por un Tribunal CIADI en el caso Fedax, N. V. c. República de Venezuela. ${ }^{53}$

\section{EL ARBITRAJE DEL CIADI ES AUTÓNOMO E INDEPENDIENTE}

Tal vez la característica más importante que diferencia el arbitraje del CIADI de cualquier otro tipo de arbitraje comercial es la completa autonomía e independencia del procedimiento. Las reglas de arbitraje del CIADI tienen un carácter internacional, puesto que se fundamentan en un tratado. Estas reglas tienen un carácter autónomo, en el sentido de que son independientes del derecho nacional (incluso por lo que respecta al

50 Véase a este respecto la decisión sobre competencia de fecha 14 de abril de 1988 en el caso Southern Pacific Properties (Middle East) Limited c. República Árabe de Egipto, ICSID Reports, vol. III, p. 143.

51 Esta situación se contempla, por ejemplo, en los casos del Tratado bilateral entre Jamaica y Estados Unidos de 1994, del Tratado bilateral entre Jamaica y Argentina de 1994, del Tratado bilateral entre Turquía y Gran Bretaña (1991) y del Tratado bilateral entre Jamaica y Dinamarca de 1990.

52 Véase, por ejemplo: Ceskoslovenska Obchodni Banka, A. S. c. República Eslovaca (Caso CIADI núm. ARB/97/4), Decisión sobre competencia de fecha 24 de mayo de 1999, www.worldbank.org/icsid (online decisions); Liberian Eastern..., cit., nota 38, p. 349; Fedax, N. V. c. República de Venezuela (Caso CIADI núm. ARB/96/3), Decisión sobre la competencia de fecha 11 de julio de 1997, International Legal Materials, vol. 37, 1998, p. 1378.

53 Fedax, N. V...., cit., nota 52, pp. 1382 y ss. 
lugar del arbitraje o al Estado en cuyo territorio se buscará el reconocimiento del laudo), y no son sujeto de control por parte de los tribunales nacionales. ${ }^{54}$ En efecto, los únicos controles que existen son aquellos bajo el convenio, a saber, aquel efectuado por el secretario general al momento de presentarse una solicitud de arbitraje, aquel ejercido por los propios tribunales de arbitraje, y aquel disponible al final del procedimiento cuando alguna de las partes decide interponer alguno de los recursos previstos por el convenio. En este apartado buscaremos esbozar cómo estas características de autonomía e independencia se reflejan en diferentes niveles y etapas del procedimiento.

\section{Solicitud de arbitraje}

De acuerdo con el artículo 36(1) del convenio, tanto el Estado contratante como un inversionista de un Estado contratante pueden iniciar un procedimiento de arbitraje mediante la presentación de una solicitud de arbitraje al secretario general del centro. En la gran mayoría de los casos ha sido el inversionista el que inicia un procedimiento en contra de un Estado contratante. ${ }^{55}$

El convenio señala que dicha "solicitud debe contener los datos referentes al asunto objeto de la diferencia, a la identidad de las partes y al consentimiento de éstas al arbitraje, de conformidad con las reglas del procedimiento a seguir para iniciar... el arbitraje" ${ }^{56}$ En la regla 2 de las Reglas Procesales Aplicables a la Iniciación de los Procedimientos de Conciliación y Arbitraje (Reglas de Iniciación), se señala más en detalle la información que debe contener una solicitud. Es importante señalar que, en la práctica, además de lo que se señala en la regla 2, el Secretariado del centro, cuando se trata de inversionistas que son personas jurídicas, solicita que se presente información y documentación que indiquen que esa persona jurídica ha llevado a cabo los pasos necesarios para que se apruebe internamente la iniciación de un procedimiento de arbitraje.

De igual manera, la persona que firma la solicitud deberá mostrar que cuenta con la autorización necesaria para actuar a nombre del inversionista. ${ }^{57}$

$54 \mathrm{Al}$ respecto, véase Delaume, Georges, "L'arbitrage CIRDI", Arbitrage International. 60 ans après regard sur l'avenir, Corte de Arbitrage de la CCI, 60 Aniversario, 1984, pp. 239-248.

55 Sólo en dos casos un Estado contratante o un organismo público del Estado han iniciado el procedimiento de arbitraje, a saber: Gabón c. Société Serete S. A. (Caso CIADI núm. ARB/76/1) y Tanzania Electric Supply Co. Ltd c. IPTL (Caso CIADI núm. ARB/98/8).

56 Artículo 36(2) del convenio.

57 Véase artículo 18 de las Reglas de Arbitraje. 
El secretario general del CIADI revisa la solicitud y no la registra de estar "manifiestamente fuera de la jurisdicción del centro" según lo dispone el artículo 36(3) del convenio. Por lo tanto, un solicitante debe indicar en su solicitud de arbitraje toda la información y explicaciones necesarias que permitan al secretario general evaluar la solicitud. De esta manera, el solicitante debe abordar en su solicitud todos los aspectos relativos a la jurisdicción del centro, a saber: si la operación en cuestión constituye una inversión conforme al convenio; si se trata de una diferencia jurídica relativa a una inversión; la nacionalidad del inversionista, e indicar si se trata de un inversionista de un Estado contratante; indicar que la contraparte es un Estado contratante (o una subdivisión política u organismo público); ${ }^{58}$ la base del consentimiento de las partes al arbitraje.

Cuando se invoca un tratado o una ley sobre inversiones como base del consentimiento, en la solicitud se deberá agregar toda la información y documentación necesaria para que se considere que dicho consentimiento cubre la diferencia en cuestión. Es decir, el solicitante deberá señalar si la operación en cuestión está cubierta por el tratado o ley y que se considera una inversión conforme a las disposiciones de esos instrumentos; si la diferencia está cubierta por el tratado; y en general si se han cumplido con todos los requisitos previstos por el tratado o ley para recurrir al arbitraje.

Es obvio que la complejidad de una solicitud de arbitraje puede incrementarse considerablemente cuando ésta se basa en un tratado o una ley. En particular, cuando el instrumento en cuestión presenta un grado de complejidad. De esta manera, si la solicitud de arbitraje funda el consentimiento en un tratado bilateral, ésta deberá cubrir todos los requisitos señalados en el tratado y en el convenio.

En el caso particular del TLCAN, la solicitud de arbitraje debe de cubrir todos los requisitos señalados por el TLCAN y aquellos señalados en el Mecanismo Complementario. ${ }^{59}$ Las solicitudes de arbitraje presentadas conforme al Mecanismo Complementario deben de reunir todos los requisitos de la jurisdicción del CIADI bajo el convenio, excepto aquellos que justamente hacen aplicables el Mecanismo Complementario. Cabe

58 En estos dos casos, la solicitud deberá indicar si se trata de organismos o subdivisiones designadas por el Estado contratante y si se tiene la aprobación prevista por el artículo 25(3) del convenio.

59 Hasta la fecha actual, el convenio no se puede aplicar porque ni Canadá ni México son Estados contratantes del CIADI. 
mencionar que puede ser que los requisitos previstos por el TLCAN se cumplan, y no lo previsto por el Mecanismo Complementario, o viceversa, y en tales casos el registro de la solicitud de arbitraje podrá ser denegada.

Como se indicó, el secretario general tiene la facultad de denegar el registro de una solicitud si considera, con base en la información presentada por el solicitante, que ésta cae manifiestamente fuera de la jurisdicción del centro. Este poder de "filtración" del secretario general tiene como objetivo evitar que un solicitante intente un arbitraje en contra de otra parte (en particular un Estado) cuando es manifiesto que no cumple con los requisitos del convenio. ${ }^{60}$ Frente a la multiplicación, particularmente, de tratados bilaterales sobre inversiones, esta facultad, aunque limitada, del secretario general otorga aún mayor seguridad jurídica a los participantes del sistema del CIADI. En efecto, ambas partes tendrán la seguridad de que el Secretariado llevará a cabo un primer escrutinio de las solicitudes de arbitraje, y evitará así el inició de un procedimiento que resultaría a todas luces infructuoso e implicaría gastos innecesarios para ambas partes. Cabe aclarar que el registro de una solicitud de arbitraje se hace sin perjuicio de cualquier excepción a la jurisdicción del centro o la competencia del tribunal que cualquiera de las partes pudiese presentar. ${ }^{61}$

Al registrarse una solicitud, el secretario general notifica a las partes del registro, y las partes deberán entonces hacer lo conducente para la constitución del tribunal de arbitraje.

\section{Constitución y poderes del tribunal}

El tribunal de arbitraje se constituye de conformidad con el acuerdo de las partes. De existir un acuerdo previo respecto al número de árbitros y al método de constitución del tribunal, éste es por lo general comunicado al centro desde la solicitud de arbitraje. Si no se hiciese así, se podrá hacer en cualquier momento después de la notificación del registro de la solicitud de arbitraje. De no existir un acuerdo entre las partes, el tribunal se compondrá de un árbitro único o de un número impar de árbitros, nombrados según lo acuerden las partes. ${ }^{62}$ Excepto tres $\operatorname{casos}^{63}$ en los cuales el

60 Véase op. cit., nota 4, pp. 7 y 8.

61 Véase artículo 41 del convenio.

62 Artículo 37 del convenio.

63 A saber: Philippe Gruslin c. Malasia (Caso CIADI núm. ARB/94/1 y Caso núm. ARB/99/3), y Misima Mines Pty. Ltd. c. Papua Nueva Guinea (Caso CIADI núm. ARB/96/2). 
tribunal se integró por un árbitro único, a la fecha, en todos los demás casos, los tribunales se han integrado por tres árbitros. La regla 2 de las Reglas de Arbitraje dispone un procedimiento a seguir a falta de acuerdo previo de las partes. De esta manera, las partes, y en particular el demandante, tienen la posibilidad de seguir este procedimiento y hacer lo más expedito posible la constitución del tribunal. Cabe señalar que esta regla indica que si no existe acuerdo de las partes luego de transcurridos 60 días a partir de la fecha de registro de la solicitud, se podrá aplicar, a solicitud de parte, el método previsto en el artículo 37(2)(b) del convenio.

Dicho artículo establece que si las partes no llegan a un acuerdo sobre el número de árbitros y el método para el nombramiento de los mismos, el tribunal se integrará por tres árbitros: uno nombrado por cada parte y el tercero, que presidirá el tribunal, nombrado de común acuerdo.

En la práctica, existe en algunas ocasiones una confusión respecto a la manera de activar el procedimiento del mencionado artículo. A veces se piensa, erróneamente, que transcurridos los 60 días, este artículo se aplica de manera automática. Sin embargo, la parte interesada debe informar al secretario general que, habiendo transcurrido los 60 días prescritos por la regla 2 de las Reglas de Arbitraje, opta por la aplicación del artículo 37(2)(b) del convenio. El secretario general notificará entonces a la otra parte lo anterior, y quedará entonces definido el número de árbitros y el método de nombramiento de éstos.

En otras ocasiones, las partes se ponen de acuerdo en el número de árbitros, pero omiten hacerlo respecto al método de su nombramiento. En caso de que no se llegue a un acuerdo respecto al método del nombramiento del o los árbitros se puede invocar el artículo 37 (2)(b) del convenio.

En el artículo 38 del convenio se precisa que si transcurridos 90 días a partir de la notificación del acto de registro de la solicitud no se ha constituido el tribunal, el presidente del Consejo Administrativo del CIADI, a petición de cualquiera de las partes, podrá nombrar el o los árbitros que faltaren. En varias ocasiones el presidente ha nombrado árbitros. Esto sucede generalmente cuando una parte no nombra un árbitro ${ }^{64} \mathrm{o}$ cuando las partes no se ponen de acuerdo respecto al nombramiento del presidente del tribunal. ${ }^{65}$

64 Por ejemplo, en el caso Patrick Mitchell c. República Democrática del Congo (Caso CIADI núm. ARB/99/7), el presidente nombró a dos árbitros, uno de los cuáles fue también designado como presidente del tribunal.

65 Este fue el caso en Pey Casado y Fundación presidente Allende c. República de Chile. 
Uno de los poderes más importantes es que el tribunal resuelve sobre su propia competencia, ${ }^{66}$ es lo que se conoce como kompetenz-kompetenz en alemán, y es un poder reconocido a toda institución de carácter judicial. Esta misma facultad se contiene en el artículo 36(6) del Estatuto de la Corte Internacional de Justicia, así como en los diferentes reglamentos de arbitraje, ya sea de carácter institucional ${ }^{67} \mathrm{o}$ ad hoc. ${ }^{68}$

Este poder de un Tribunal CIADI fue reconocido por una Corte local en relación con el caso Mobil Oil Corporation y Otros c. Nueva Zelandia (Caso CIADI núm. ARB/87/2). En efecto, después de la notificación del Acto de Registro por parte del Secretariado del centro en abril de 1987, el gobierno de Nueva Zelandia solicitó ante una corte local que se impidiera a Mobil Oil Corporation continuar con el procedimiento ante el CIADI, indicando que el Tribunal CIADI era incompetente para conocer de la diferencia. La corte, después de citar el artículo 41 del convenio, resolvió que: "I think that the use of a less precise description of the legal proceedings, which may be the subject of a stay, is because the Convention requires all those matters to be dealt with by the Tribunal... I uphold Mr. Williams' submissions that Article 41 has a significant impact on the way in which one is to interpret Section 8". ${ }^{69}$

La corte suspendió el procedimiento hasta en tanto el Tribunal CIADI no resolviera sobre su propia competencia. Esta decisión reafirmó la autonomía e independencia del arbitraje del CIADI.

De acuerdo con el convenio, ${ }^{70}$ toda excepción a la competencia del tribunal deberá ser considerada por el mismo y éste decidirá si ha de resolverla como cuestión previa o conjuntamente con el fondo de la cuestión.

En la práctica, muchos tribunales CIADI deciden resolver las excepciones a la jurisdicción de manera previa. ${ }^{71}$ En otras ocasiones los tribunales han decido unir las excepciones al fondo de la cuestión. ${ }^{72}$

66 Artículo 41 del convenio.

67 Por ejemplo, el artículo 6o.(2) del Reglamento de Arbitraje de la CCI.

68 Por ejemplo, el artículo 21 del Reglamento de Arbitraje de la CNUDMI.

69 High Court, Wellington, 1 de julio de 1987, ICSID Reports, vol. 4, p. 128.

70 Artículo 41(2).

71 Este fue el caso en Waste Management Inc. c. Estados Unidos Mexicanos (Caso CIADI núm. ARB/AF/98/2), Laudo declinando competencia y opinión disidente del 2 de junio de 2000, www.worldbank.org/icsid.

72 Fue el caso en Compañía de Aguas del Aconquija, S. A. y Vivendi Universal c. República Argentina (Caso CIADI núm. ARB/97/3), Laudo del 21 de noviembre de 2000, International Legal Materials, vol. 40, p. 457, 2001 (trad. al español publicada en La Ley, Buenos Aires, año LXV, núm. 25,5 de febrero de 2001, p. 1). 
En varias ocasiones, las excepciones a la competencia se presentan aún antes de que se constituya el tribunal, o antes o durante la primera sesión del tribunal con las partes, lo que permite al tribunal respectivo fijar, después de consultar con las partes, un calendario para la presentación de escritos. Sin embargo, la regla 41 del Reglamento de Arbitraje dispone que las excepciones a la competencia se deberían interponer lo antes posible, pero en todo caso a más tardar antes del vencimiento del plazo para la presentación del memorial de contestación. Dicha regla precisa que si se tratare de una excepción que se refiere a una demanda subordinada, la excepción deberá de presentarse a más tardar al momento de la réplica.

\section{Protección diplomática}

Las diferencias en materia de inversiones han dado lugar en varias ocasiones a que los Estados actúen en defensa de los intereses de sus nacionales en contra de otros Estados. Entre los objetivos del convenio se encuentra el despolitizar las diferencias en materia de inversiones. Así, se tiene que evitar que un Estado pueda paralelamente a un procedimiento de arbitraje efectuar una reclamación internacional en contra de un Estado receptor de inversión por una diferencia ocurrida con uno de sus nacionales que hubiese invertido en ese Estado, tomando en consideración que este último hubiese recurrido al centro para resolver tal diferencia. De esta manera, la prohibición de conceder la protección diplomática se estipuló en el artículo 27 del convenio, ${ }^{73}$ con el fin de otorgar la seguridad jurídica necesaria al Estado parte en la diferencia de que no sería objeto de reclamaciones paralelas, una por el Estado y otra por el inversionista. ${ }^{74}$ Cabe señalar que esta prohibición queda sin efecto si existe un incumplimiento por parte del Estado parte en la diferencia de un laudo dictado por un tribunal.

Sin embargo, para evitar darle una estructura muy estricta a la renuncia efectuada por el Estado, el convenio dispuso la posibilidad de que se

73 Cualquier renuncia unilateral por parte del inversionista no sería oponible a su Estado nacional.

74 Se puede decir que por medio de esta renuncia a la protección diplomática se permite lo que la "Cláusula Calvo" quería conseguir. Esta disposición tiene, por lo tanto, particular importancia para los países latinoamericanos. Para tener una visión más detallada de la relación entre los principios incorporados en la Cláusula Calvo y los principios del arbitraje del CIADI, véase Shihata, Ibrahim F. I., op. cit., nota 6, pp. 309 y ss. 
llevaran a cabo gestiones diplomáticas informales que tengan como único fin facilitar la resolución de la diferencia.

La obligación contenida en el artículo 27 del convenio es una obligación internacional que se aplica a todos los Estados contratantes del convenio cuando uno de sus nacionales y otro Estado contratante hayan consentido en someter la diferencia a la jurisdicción del centro. La violación de esta obligación internacional podría constituir un acto ilícito internacional por parte del Estado contratante. Algunos autores han considerado que una reclamación interestatal presentada en violación del artículo 27 ante un tribunal internacional debería tener como efecto que éste se declarara incompetente para conocer del caso. ${ }^{75}$

\section{A. Autonomía del laudo ${ }^{76}$}

De acuerdo con el artículo 53 del convenio, el laudo es obligatorio y no puede ser objeto de apelación, ni cualquier otro recurso, excepto aquellos previstos en el mismo convenio. Este artículo deja muy claro que los laudos dictados por un tribunal del CIADI no pueden ser anulados ni revisados por ningún tribunal local. En efecto, en el caso de los laudos dictados por un Tribunal del CIADI no es ni siquiera necesario el exequatur del mismo, ${ }^{77}$ puesto que todo Estado contratante deberá reconocer al laudo carácter obligatorio y deberá ejecutar las obligaciones pecuniarias impuestas por un laudo como si se tratare de una sentencia firme dictada por un tribunal nacional. El convenio además precisa que "El Estado contratante que se rija por una constitución federal podrá hacer que se ejecuten los laudos a través de sus tribunales federales y podrá disponer que dichos tribunales reconozcan al laudo la misma eficacia que a las sentencias firmes dictadas por los tribunales de cualquiera de los estados que lo integran". ${ }^{78}$ Así, un laudo del CIADI se considera como res judicata y no

75 Véase Amerasinghe, C. F., "The Jurisdiction of the International Centre for the Settlement of Investment Disputes”, Indian Journal of International Law, vol. 19, 1979, pp. 226 y 227; Schreuer, Christoph, The ICSID Convention: A Commentary, Cambridge, Cambridge University Press, 2001, p. 399.

76 Para un análisis de las características de un laudo de un tribunal del CIADI, véase Broches, Aron, "Awards Rendered Pursuant to the ICSID Convention: Binding Force, Finality, Recognition, Enforcement, Execution”, ICSID Review, Foreign Investment Law Journal, vol. 2, núm. 2, 1987, pp. 292 y ss.

77 Esto fue confirmado por la Corte de Apelaciones de París en una decisión relativa al laudo del caso Benvenutti y Bonfant c. la República del Congo. Véase Revue de l'Arbitrage, París, Cour d'Appel, decisión del 26 de junio de 1981, vol. 207, pp. 208 y 209.

78 Artículo 54(1) del convenio. 
admite revisión por autoridad local alguna. Esto constituye una de las grandes innovaciones del CIADI, y hasta ahora ninguna institución de arbitraje tiene una característica similar.

De esta manera, es suficiente presentar una copia certificada por el secretario general del centro ante los tribunales competentes o ante cualquier otra autoridad designada por el Estado respectivo, ${ }^{79}$ para que el procedimiento de ejecución del mismo se inicie conforme a lo previsto en la legislación local.

\section{B. Autonomía del sistema}

La autonomía del sistema CIADI se reafirma cuando el artículo 53 del convenio señala que un laudo admite sólo los recursos que el mismo convenio establece, a saber: rectificación o requerimiento de decisión complementaria, aclaración, revisión y anulación.

De acuerdo con el artículo 49(2) del convenio, las partes pueden presentar un requerimiento, dentro de los 45 días después de la notificación del laudo, solicitando la resolución de un punto que se haya omitido o la rectificación de errores materiales, aritméticos o similares contenidos en el laudo. El tribunal, previa notificación a la otra parte, podrá decidir a este respecto. En la práctica del centro, se han presentado cuatro de estos requerimientos, y uno de ellos se encuentra actualmente pendiente..$^{80}$

Cuando existiese una diferencia entre las partes acerca del sentido o alcance del laudo, cualquiera de las partes podrá, mediante escrito dirigido al secretario general, solicitar que se aclare el sentido del mismo. ${ }^{81} \mathrm{El}$ secretario general buscará que el mismo tribunal que dictó el laudo aclare el alcance del mismo, y de no ser posible se constituirá un nuevo tribunal.

El recurso de revisión tiene por objeto otorgar a cualquiera de la partes la posibilidad de solicitar la revisión del laudo cuando se descubra un hecho que pueda influir en la conclusión del mismo, y del cual ni la parte que solicita la revisión ni el tribunal tenían conocimiento. ${ }^{82} \mathrm{El}$ convenio

79 El laudo en el caso Benvenutti y Bonfant c. la República del Congo fue el primero presentado ante un tribunal local.

80 En los siguientes casos: Amco Asia Corporation y Otros c. República de Indonesia (Caso CIADI núm. ARB/81/1)-Resometimiento; Liberian Eastern Timber Corporation c. República de Liberia (Caso CIADI núm. ARB/83/2); Emilio Agustín Maffezini c. Reino de España (Caso CIADI núm. ARB/97/7); Alex Genin y Otros c. República de Estonia (Caso CIADI núm. ARB/99/2) (pendiente). En algunos de estos casos, las decisiones han sido publicadas. Para obtener los datos de publicación consultar: www.worldbank.org/icsid (rubro ICSID Cases/concluded Cases)

81 Artículo 50 del convenio.

82 Artículo 51 del convenio. A la fecha se ha interpuesto un solo recurso de revisión. Esto sucedió 
establece dos términos perentorios para la interposición de este recurso. Por un parte, éste deberá ser interpuesto dentro de los noventa días siguientes al que se tuvo conocimiento del hecho, y por la otra parte, éste sólo puede interponerse dentro de los tres años siguientes a que se dictó el laudo. Además, el convenio indica que de ser posible el mismo tribunal que dictó el laudo conocerá del recurso, y que éste podrá suspender la ejecución del laudo si las circunstancias lo exigen. Si la parte que interpuso el recurso solicita la suspensión de la ejecución del laudo, la ejecución se suspenderá hasta en tanto el tribunal decida lo conducente. En la práctica, la otra parte podría exigir el depósito de una garantía para la suspensión de la ejecución del laudo, y será el tribunal el que deba considerar las circunstancias del caso para exigir o no tal garantía, y el monto de la misma. Lo anterior se aplica también a los procedimientos de anulación.

El último recurso que establece el convenio es el de la anulación del laudo. El convenio establece limitativamente las causas por las que una parte puede interponer un recurso de anulación, a saber: a) que el tribunal se hubiere constituido incorrectamente; $b$ ) que el tribunal se hubiere extralimitado manifiestamente en sus facultades; $c$ ) que hubiere habido corrupción de algún miembro del tribunal; $d$ ) que hubiere quebrantamiento grave de una norma del procedimiento; o $e$ ) que no se hubieren expresado en el laudo los motivos en que se funde.

Hasta la fecha actual se han interpuesto nueve recursos de anulación. Entre 1985 y 1992 se interpusieron seis, de los cuales los dos casos más conocidos son Klöckner Industrie-Anglagen GMBH y Otros c. la República Unida del Camerún y Amco Asia Corporation y Otros c. República de Indonesia. ${ }^{83}$

en el caso American Manufacturing \& Trading, Inc. c. República Democrática del Congo (Caso CIADI núm. ARB/93/1). En este caso, hubo una avenencia de las partes y se dio por terminado el procedimiento de conformidad con la regla 44 de las Reglas de Arbitraje. Véase: www.worldbank.org/icsid (rubro ICSID Cases/ Concluded Cases).

83 Los otros dos casos en donde se interpuso un recurso de anulación en este periodo de 1985 a 1992 son: Southern Pacific Properties Middle East Limited c. República Árabe de Egipto; en este caso el procedimiento se dio por terminado porque las partes llegaron a una avenencia; y Maritime International Nominees Establishment c. República de Guinea, en este caso el laudo fue anulado parcialmente mediante decisión del comité ad hoc de fecha 22 de diciembre de 1989, en: ICSID Reports, vol. 4, 1997, pp. 79 y ss. Respecto a una opinión positiva del procedimiento de anulación, véase Broches, Aron, "Observations on the Finality of ICSID Awards", ICSID Review, Foreign Investment Law Journal, vol. 6, núm. 2, 1991, pp. 321-379; Broches, Aron, "On the Finality of Awards: A Reply to Michael Resiman", ICSID Review, Foreign Investment Law Journal, vol. 8, núm. 1, 1993, pp. 92-103. Caron, David D., "Reputation and Reality in the ICSID Annulment Process: Understanding the Distinction Between Annulment and Appeal”, ICSID Review, Foreign Investment Law Journal, vol. 7, núm. 1, 1992, pp. 21-56. Respecto a una opinión pesimista a este respecto: Reisman, W. Mi- 
En estos dos casos se inició un primer procedimiento de anulación, cuyas respectivas decisiones anularon el laudo que en cada caso se había dictado. ${ }^{84}$ En ambos casos se sometió de nueva cuenta la diferencia al arbitraje del CIADI, y para cada caso se constituyó en consecuencia un nuevo tribunal. En el caso Klöckner se dictó un nuevo laudo el 26 de enero de 1988, y se interpuso de nueva cuenta un recurso de anulación en contra de éste segundo laudo. El Comité de Anulación rechazó la solicitud de anulación el 17 de mayo de 1990. ${ }^{85}$ En el caso Amco Asia se dictó un laudo el 5 de junio de 1990, así como una decisión sobre decisiones adicionales, y una rectificación del laudo el 17 de octubre de 1990. Se interpuso un segundo recurso de anulación, y el Comité de Anulación decidió rechazar las solicitudes de anulación presentadas por las partes respecto del laudo, y anular la decisión sobre decisiones adicionales y la rectificación del laudo, mediante decisión de fecha 17 de diciembre de 1992. ${ }^{86}$

El convenio, mediante el establecimiento de recursos bien definidos en contra del laudo, y garantizando que será un comité ad hoc de tres miembros, nombrados por el presidente del Consejo Administrativo de la lista de árbitros del centro, quien decidirá la anulación, otorga seguridad jurídica a las partes e independencia cualquier sistema judicial nacional. ${ }^{87}$

Después de prácticamente diez años de que el centro no había registrado una solicitud de anulación, en este año fiscal de 2001 se iniciaron tres procedimientos de anulación en los casos siguientes: Philippe Gruslin c. Malasia; Compañía de Aguas del Aconquija, S. A. y Vivendi Universal c. República Argentina; y Wena Hotels Limited c. República Árabe de Egipto. En el primer caso, la parte demandante inició el procedimiento de anulación en contra de un laudo por el cual el respectivo tribunal de arbitraje declinaba su competencia para conocer del fondo del asunto. En el

chael, "Repairing ICSID's Control System: Some Comments on Aron Broches 'Observations on the Finality of ICSID Awards"”, ICSID Review, Foreign Investment Law Journal, vol. 7, núm. 1, 1992, pp. 196-211.

84 La decisión del Comité ad hoc en el caso Klöckner se publicó en: ICSID Reports, vol. 1, 1993, pp. 509 y ss. La decisión del comité ad hoc en el caso Amco Asia se publicó en: ICSID Reports, vol. 2, 1994, pp. 95 y ss.

85 Decisión inédita.

86 Idem.

87 Esto no sucede respecto de los laudos dictados al amparo de las Reglas del Mecanismo Complementario. En este caso, los laudos, como en cualquier arbitraje comercial internacional, están sujetos a la revisión de cortes nacionales. Véase la decisión de la Suprema Corte de British Columbia, Canadá, de fecha 2 de mayo de 2001 en el caso Metalclad Corporation c. los Estados Unidos Mexicanos, http://www.worldbank.org/icsid/cases/awards.htm\#award8. 
segundo caso, las demandantes iniciaron el procedimiento de anulación respecto de un laudo que rechazó su reclamación sobre el fondo. En el tercer caso, la parte demandada solicitó la anulación de un laudo en su contra.

\section{CONCLUSIÓN}

El número importante de cláusulas CIADI en tratados, leyes y contratos confirma que los esfuerzos del banco para crear esta organización internacional, hace cerca de 40 años, han dado sus frutos. La especialización del arbitraje del CIADI y la complejidad de algunos tratados han llevado a que este tipo de arbitraje internacional sea cada vez más complejo. En virtud del gran número de tratados sobre inversión que se han concluido, se prevé un creciente número de casos ante el CIADI, por lo que seguramente muchos asuntos e interrogantes aún pendientes sobre la interpretación del convenio y la aplicación de los tratados de inversión serán motivo de discusión y resolución en los tribunales del CIADI. Se espera así que el CIADI siga contribuyendo al desarrollo, no sólo del arbitraje internacional, sino del derecho internacional sobre inversión. 